Submission ID: 43980

\title{
Domanik Formaiton: Exploration Criteria and Program
}

A. Gabnasyrov* (JSC "LUKOIL-Engemeering" "PermNIPIneft" Perm branch), V. Voytko (JSC "LUKOIL-Engemeering" "PermNIPIneft" Perm branch), S. Soloviev (JSC "LUKOIL-Engemeering" "PermNIPIneft" Perm branch)

\section{SUMMARY}

The main purpose of the work is evaluation of the potential of oil source rocks of the Domanik age in the Volga-Ural and Timan-Pechora oil and gas provinces as a unconventional hydrocarbon source on the basis of generalization of the materials of earlier completed and new standard and special core studies. The maps of the content and maturity of organic matter were built, the lithological composition of the Domanik horizon was evaluated, and the comparative evaluation of the domanikite parameters at the commercially developed field-analog Eagle Ford was performed. The work program for additional study of the potentials of Donamik deposits within the work area of LUKOIL PJSC in 2016-2017 was compiled. 


\title{
Доманиковая формация: критерии перспективности и программа опытных работ
}

\author{
А.В. Габнасыров*,В.Л. Войтко, С.И. Соловьев (Филиал ООО «ЛУКОЙЛ-Инжиниринг» \\ «ПермНИПИнефть» в г. Перми)
}

\section{Введение}

Как известно, новые открытия месторождений на суше, в уже известных провинциях не предлагают нам больших и тем более гигантских месторождений, запасы открытых месторождений из года в год мельчают, находить их становится все труднее и специалисты и менеджеры компаний обращают внимание на новые, нетрадиционные источники УВ, а нетрадиционные источники УВ требуют нетрадиционных подходов и изменения видения всего цикла от ГРР до технологий добычи нефти.

В работе рассмотрены отличия традиционных источников УВ от нетрадиционных, мировой опыт изучения последних и статистика основных геологических параметров по наиболее известным сланцевым резервуарам. На основе имеющейся информации проведено сравнение доманикитов с северо-американскими сланцевыми месторождениями разработке новых поисковые критериев для разведки доманиковых отложений на территории деятельности ПАО «ЛУКОЙЛ» в Волго-Уральской (Пермский край) и Тимано-Печерской (Республика Коми, НАО) провинциях.

\section{Теория}

Условно, можно структурировать ресурсы сланцевых углеводородов на 3 типа:

1. находящиеся в «нормальном» коллекторе - такие запасы, можно вырабатывать без применения специальных технологий. Чаще всего, к этой категории относятся все ранее сделанные открытия в доманиковых отложениях;

2. низкопроницаемая часть сланцевой толщи, которая может разрабатываться только при условии создания стимулированного объема коллектора $(Г \mathrm{C}+$ разветвленная сеть трещин МГРП);

3. в перспективе, возможно, термические методы позволят реализовывать непреобразованное ОВ в УВ в промышленном масштабе;

Ввиду сильной неоднородности сланцевых толщ типы 1 и 2, как правило, встречаются вместе, тем ни менее, в своей работе мы направляем усилия на локализацию территорий с максимально хорошими ФЕС.

На основе мирового опыта, был определен аналог доманиковой формации - сланцевый плей США Eagle Ford и предложены критерии для проведения поисков перспективных зон (Рис. 1). На сегодняшний день критерии поисков УВ в доманиковой формации видятся следующими [1,2]:

1. Наличие пропластков с высоким содержанием органического вещества II типа (>5\%) говорит о высоком нефтематеринском потенциале данных отложений [8,9];

2. Зрелость органического вещества $1.2>$ Ro > 0.85 свидетельствует о значительной степени преобразованности ОВ, что ведет к увеличению проницаемости за счет с генерацией легкой нефти и возможного увеличения пористости керогена. Для успешного освоения нетрадиционных отложений доманика, необходимо решить ряд вопросов, одним из которых является изменение структуры и текстуры органического вещества в процессе катагенеза. Решение данного вопроса является обязательным для получения промышленных притоков нефти из материнских пород, т.к. позволит уточнить поисковые критерии и более достоверно локализовать перспективные для коммерческой добычи зоны пласта [4,5,6,7];

3. Благоприятные геомеханические условия, обусловленные хрупкими породами и как следствие развитой трещиноватостью (4) позволяют эффективно проводить ГРП и максимизации дренируемого объема и дебита нефти;

4. Наличие АВПД и/или естественной трещиноватости обеспечивающих локальное увеличение проницаемости; 


\section{EAGE}

Т.к. доманикиты относятся к карбонатным породам с малой глинистостью, то низкой эффективности ГРП (при правильной реализации - большеобъемные высокоскоростные закачки) не ожидаются. Значит, остается определить участки с высокими концентрациями хорошо преобразованного ОВ, которые и будут первоочередными объектами ГРР.

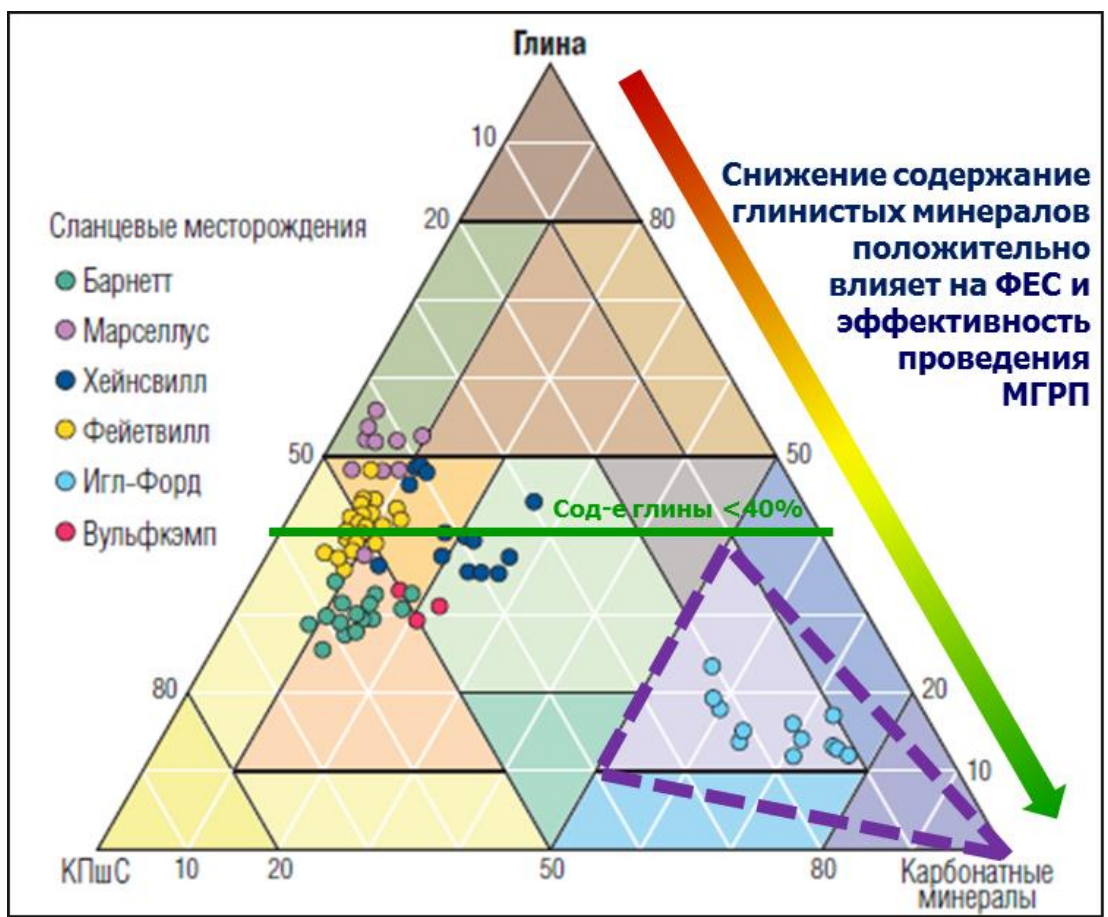

Рисунок 1 сопоставление минералогического состава сланцевых плеев США (точки) и доманиковой формации (полигон ограниченный пунктирной линией)

\section{Результаты работ}

На первом этапе изучения потенциала доманикитов как источника сланцевой нефти была выполнена оценка распространения глубоководных фаций (соответствующих доманикитам) на исследуемых территориях. Далее, на основе бассейнового моделирования уточнены региональные закономерности преобразованности органического вещества доманикового горизонта на востоке Пермского края. Что позволило, путем «суммирования» карт содержания органического вещества (Сорг) и распределения степени преобразованности органического вещества [3] выделены наиболее перспективны зоны дальнейшего изучения по аналогии с опытом США (таблица 1).

Таблица 1

Геолого-геофизическая характеристика сланцевых формаций

\begin{tabular}{|l|c|c|c|c|c|}
\hline \multicolumn{1}{|c|}{ Регион } & ТПП & ВУП & Eagle Ford & Duvernay & Woodford \\
\hline Мощность (м) & До 200 & До 50 & $16-200$ & $12-80$ & $40-80$ \\
\hline Тип керогена & \multicolumn{5}{|c|}{ II \& I } \\
\hline Обстановки осадконакопления & \multicolumn{5}{|c|}{ Морские, анаэробные } \\
\hline Содержание Сорг(\%) & \multicolumn{2}{|c|}{$1-20+$} & 4,7 & $1-20$ & 6.9 \\
\hline Водородный индекс (mg/g ТОС) & \multicolumn{2}{|c|}{$242-600$} & 650 & 500 & 375 \\
\hline Зрелость (Rо\%) & \multicolumn{2}{|c|}{$0,5-1,1 *$} & 0,74 & 1,25 & 1,50 \\
\hline Глубина залегания (м) & $2000-3500$ & $1800-3000$ & $1500-3500$ & $>2700$ & $2300-3500$ \\
\hline Содержание кварца (\%) & $35-95 \%$ & $10-15 \%$ & $2-40 \%$ & $3-54 \%$ & $41-75 \%$ \\
\hline Содержание карбонатов(\%) & $0-40 \%$ & $70 \%$ & $10-90 \%$ & $18-90 \%$ & $2-14 \%$ \\
\hline Пористость (\%) & \multicolumn{2}{|c|}{$9-12$} & $4-15 \%$ & $6-10 \%$ & $3-9 \%$ \\
\hline Проницаемость (mD) & $20-180$ & $400-1000$ & $400-1000 \mathrm{nD}$ & н/д & $1-1000 \mathrm{nD}$ \\
\hline Наличие АВПД & Да, Нет & $\mathrm{nD}$ & $\mathrm{AB \Pi}$ & АВПД & Ниже нормы \\
\hline Наличие промышленных притоков & $80+$ т/сут. & До 10 т/сут & Да & Да & Да \\
\hline
\end{tabular}


Одновременно с этими работами был проведен анализ минерального состава и оценка индекса насыщенности (OSI) по методике Д. Джарви, учитывающей адсорбцию УВ органическим веществом (рис. 2). Результаты оценки OSI по керну, свидетельствуют о возможной продуктивности нетрадиционных коллекторов, но требуют продолжения работ в этом направлении и учета индивидуальных особенностей ОВ доманикитов.

В ходе анализа геолого-геофизических и геохимических характеристик, так же установлено, что средние показатели доманикитов находятся на уровне разрабатываемых сланцевых месторождений США.

Кроме того, установлено, что все скважины с притоками полученные из непосредственно толщи обогащенной органическим веществом или прилегающих к ней плотных пластов располагаются в непосредственной близости от разрывных нарушений. В этой связи, ведется работа по оценке перспектив добычи углеводородов из трещинного коллектора доманиковой формации.

Для продолжения работы, была составлена целевая программа изучения, основанная на передовом мировом опыте. Программа учитывает комплекс геохимических, геомеханических и других видов петрофизических исследований, как на керне, так и в скважинах, с целью углубления знаний о геологическом строении сланцевых залежей доманикитов и оптимизации подходов к ГРР и проектированию разработки. Для отработки технологий заканчивания и оценки добычного потенциала, на одном из месторождений ПАО «ЛУКОЙЛ» запланировано бурение опытной ячейки из $4 \mathrm{x}$ скважин с горизонтальными окончаниями $\sim 1000 \mathrm{M}$ и многостадийным ГРП.

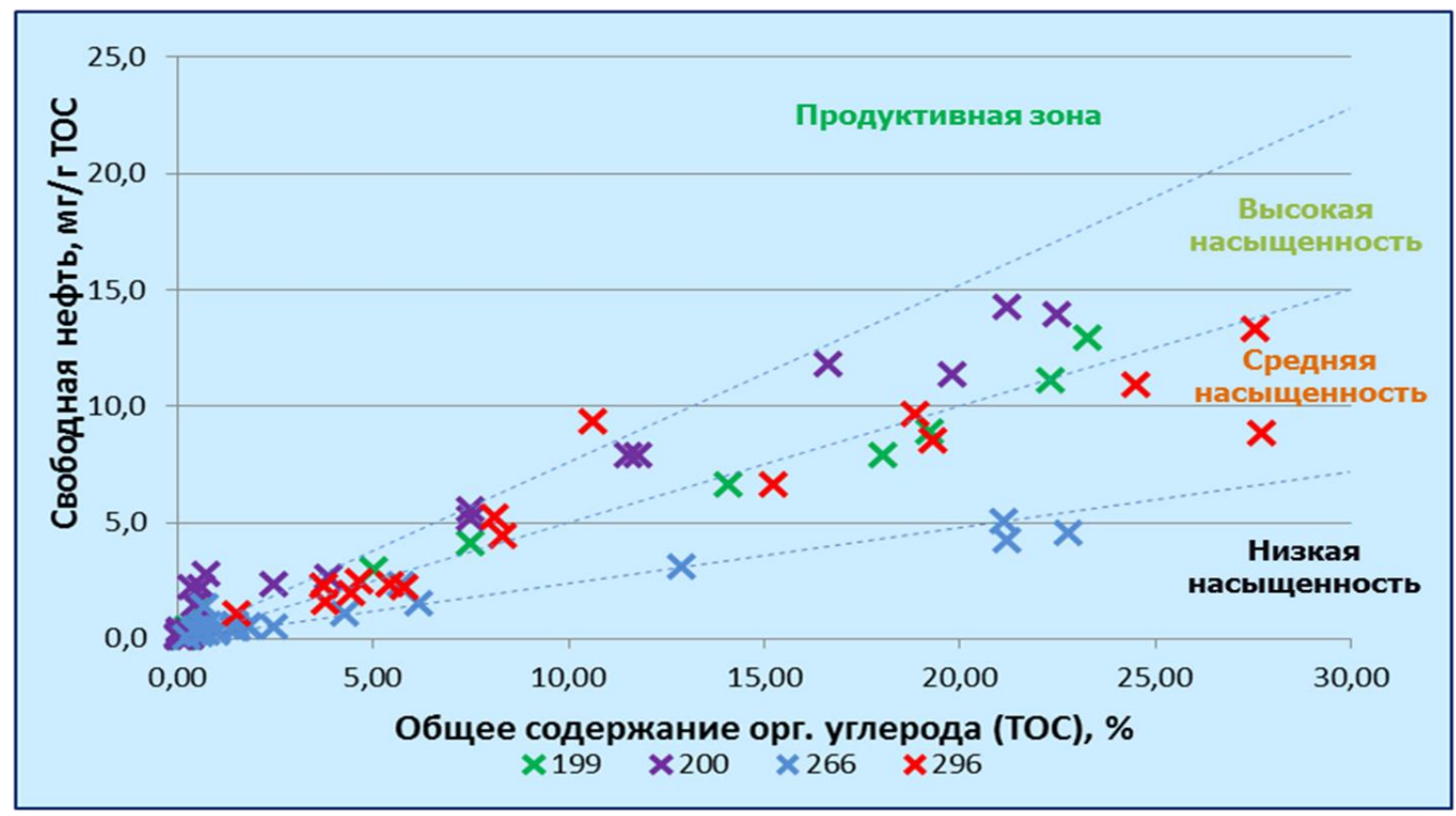

Рисунок 2 сопоставление удельного содержания свободной нефти с общим содержанием органического вещества.

\section{Выводы}

1. Проведено глобальное обобщение геолого-геофизической информации по территории ВУП и ТПП с целью оценки потенциала нефтематеринских пород доманикового типа как источника сланцевой нефти;

2. Доманикиты отличаются высокими содержанием органического углерода (TOC $=5,03$ $23,29 \%$ масс.), значением водородного индекса (HI=412-516 мг УВ/г ТОС) и содержат высококаче-ственное сапропелевое органическое вещество II типа. Преобразованность ОВ соответствует главной зоне нефтеобразования на стадиях мезокатагенеза МК1-начало МК-3; 
3. Проведена сравнительная оценка характеристик доманикитов с промышленно разрабатываемыми месторождениями США и Канады. Результаты анализа показали, что доманикиты не уступают, а по некоторым критериям и превосходят разрабатываемы сланцевые плеи;

4. Сравнительный анализ геологических характеристик пород доманиковой формации и сланцевых формаций Северной Америки показал сходство доманикитов с месторождением Eagle Ford;

5. На основе обзора мирового опыта предложены критерии оценки нефтегазоносности доманиковых отложений; нефти;

6. Доманиковые отложения оценены как высокоперспективные для поисков сланцевой

7. Сопоставление карт содержания органического углерода с картами преобразованности органического вещества (Ro, \%) позволило определить участки, наиболее перспективные для геологического изучения.

8. Установлена целесообразность изучения естественной трещиноватости как одного из важных факторов получения притока из доманиковых отложений;

9. Подготовлена программа геологического изучения доманиковой формации на территории деятельности ПАО «ЛУКОЙЛ», включающая попутные исследования в поисковых скважинах, а также научно-исследовательские работы по разработке методик исследований керна;

10.На основе выполненного анализа принято решение бурения $4 \mathrm{x}$ скважин с горизонтальным окончаниями для оценки добычных характеристик пласта D3dm.

\section{Библиография}

1. Ильин Н.Ю. и др. Отчет НИР «Проведение комплексных геохимических исследований доманикитов верхнего девона с целью оценки перспектив добычи сланцевого газа и сланцевой нефти на территории Республики Татарстан»;

2. Глайзер К.С. и др. Поиск высокопродуктивных зон: и качество заканчивания в органогенных сланцах. 20 с.;

3. Соснин Н.Е. и др. Обоснование перспектив нефтегазоносности отложений доманикового типа // Отчет. 2012г.;

4. Leo Alcantar-Lopez and Steve J. Chipera. Improving Our Understanding of Porosity in Source Rock Reservoirs through Advanced Imaging Techniques. SPE 168916. 10 p.;

5. Asana Wasaki and Yucel Akkutlu. Permeability of organic-rich shales. 13p.;

6. M.E. Curtis, B.J. Cardott. The development of Organic Porosity in the Woodford shales related to thermal maturity. SPE 160158. 8 p.;

7. Albert Maende, W. David Weldon. Pyrolysis and TOC identification of tight sweet spots. SPE 168732. 11p.;

8. Hernan M. Reijenstein. Where is the Vaca Muerta sweet spot? The importance of regional facies trends, thickness, and Maturity in General play Concepts. SPE 178702. 8p.;

9. Beau Tinnin. Multi-source data integration: Eagle Ford shale sweet spot mapping. SPE 178592. 9p.;

\section{References}

1. Ilyin N.U. Research report "Complex geochemical evaluation of upper devonian domanik formation for shale gas and oil recovery assessment in Tatarstan republic";

2. Glaizer K.S. "Sweet spots prospecting and completion quality in shales";

3. Sosnin N.E. Research report "Prospective of oil-bearing capacity of Domanik formation"

4. Leo Alcantar-Lopez and Steve J. Chipera. Improving Our Understanding of Porosity in Source

Rock Reservoirs through Advanced Imaging Techniques. SPE 168916. 10 p.;

5. Asana Wasaki and Yucel Akkutlu. Permeability of organic-rich shales. 13p.; 


\section{EAGE}

6. M.E. Curtis, B.J. Cardott. The development of Organic Porosity in the Woodford shales related to thermal maturity. SPE 160158. 8 p.;

7. Albert Maende, W. David Weldon. Pyrolysis and TOC identification of tight sweet spots. SPE 168732. 11p;

8. Hernan M. Reijenstein. Where is the Vaca Muerta sweet spot? The importance of regional facies trends, thickness, and Maturity in General play Concepts. SPE 178702. 8p.;

9. Beau Tinnin. Multi-source data integration: Eagle Ford shale sweet spot mapping. SPE 178592. 9p.; 